Article

\title{
Can Law Address Intersectional Sexual Harassment? The Case of Claimants with Personality Disorders
}

\section{Karen O'Connell}

Faculty of Law, University of Technology Sydney, Sydney, NSW 2007, Australia; Karen.OConnell@uts.edu.au; Tel.: +61-2-95148079

Academic Editor: Margaret Thornton

Received: 30 September 2019; Accepted: 25 November 2019; Published: 5 December 2019

\begin{abstract}
Sexual harassment across multiple grounds, including race, disability, sexuality and age, remains an entrenched problem that is poorly dealt with in law. Prevalence rates for intersectional sexual harassment are higher for certain groups, while legal redress is low. This paper examines case law on sexual harassment in Australia where there are intersectional factors and asks whether the "intersectionality" section inserted into the federal Sex Discrimination Act in 2011 has impacted legal practice and decision-making. In particular, it considers the situation of sexual harassment claimants with behavioural and personality traits that are considered "disordered" and the specifically gendered disability stereotypes that shape their treatment in law. Recent cases in Australia dealing with the sexual harassment of people with personality disorders show that intersectionality provisions of sexual harassment laws may in fact be used to undermine a legal claim by a person with disability rather than strengthen it. This article argues that an intersectional legal feminist perspective on harassment is needed for the law to work.
\end{abstract}

Keywords: sexual harassment law; intersectionality; disability; personality disorder

\section{Introduction}

Sexual harassment is experienced differently, and often amplified, according to the race, disability, sexuality and age characteristics of the harassed person and their harasser (Buchanan et al. 2018; Chi Cantalupo 2019; Mitchell et al. 2014; Onwuachi-Willig 2018; Barnett 2017; Ramakrishnan 2011). Yet thirty years after Crenshaw (1989) first drew attention to anti-discrimination law's failure to see intersectional harms, legal responses to sexual harassment continue to "assume a generic woman victim" (Calafell 2014, p. 81). Focusing on sexual harassment laws in Australia, this article tackles the question of why, after decades of powerful critique from scholars and people with lived experience of inequality, anti-discrimination laws continue to deal so poorly with intersectionality, and how they might better address it. In particular, it considers the situation of sexual harassment claimants with behavioural and personality traits that are considered "disordered" and the specifically gendered disability stereotypes that shape their treatment in law.

In response to the problematic way that disability and gender stereotypes intersect with sexual harassment, this article argues that feminist legal theory continues to be a crucial anchoring theory for sexual harassment law and practice. I have written elsewhere about the way that feminist legal theory, for all its diversity, has an ongoing interest in making women visible in law as full legal subjects and agents of knowledge ( $\mathrm{O}^{\prime} \mathrm{C}$ onnell 2012). Sexual harassment is an exemplar of this process: it was made a legally compensable harm through feminist activism and legal theory, notably through the early work of scholar and activist MacKinnon (1979). However, feminist legal theory needs to radically engage with disability and other critical theorists to build a theoretical intersectional approach to sexual harassment. As it stands, the literature that does exist on disability and sexual harassment lies 
mostly outside of law, and there is a danger that harassment against women with disabilities will be similarly overlooked. Crenshaw and others have pointed out that "discourses of resistance", including feminism, can do the work of marginalization-for example, by privileging the experiences of white women-and so "the theory is never done, nor exhausted by its prior articulations or movements; it is always already an analysis-in-progress."(Carbado et al. 2013, p. 304). In focusing on women with purportedly difficult or non-conforming behavior, this article is directed at making visible one neglected area of intersectional sexual harassment.

We have strong laws on sexual harassment in Australia insofar as they set out an individual complaints regime to respond to already-existing sexual harassment. Despite this, there is an extremely low reporting rate for sexual harassment of any kind (17 percent; AHRC Survey 2018). The gap between harassment experiences and the social, institutional, regulatory and legal responses to intersectional sexual harassment is one aspect of that low reporting rate. Intersectional sexual harassment is the qualitatively different harassment people experience at the intersection of identity categories such as disability and sex. It can be distinguished from additive discrimination where a single person may be discriminated against on two or more separate grounds, for example, where an Aboriginal woman is excluded from a club which refuses to admit both women and non-whites (Goldblatt 2015). Intersectional sexual harassment is arguably more complex than conventional sexual harassment, as law needs to deal with the compounding effects of multiple axes of identity or experience, and so it is less likely to be reported and more likely to meet legal hurdles. Yet law has not dealt effectively with even the least complex intersectional issues. In Australia, as is set out below, one potentially useful legal tool to account for intersectional sexual harassment has not been used at all. I argue that even when there is a provision to address intersectional harassment, we do not have the underpinning understanding of particular harassment experiences that would make the law effective. An intersectional legal feminist perspective on harassment is needed for the law to work.

\section{Intersectional Sexual Harassment: Sex and Disability}

We know from empirical data that intersectional sexual harassment remains a serious problem. The Australian Human Rights Commission's National Survey on Sexual Harassment (Australian Human Rights Commission 2018), as well as related empirical work, such as the Australian Bureau of Statistics Personal Safety Survey (Australian Bureau of Statistics 2016), demonstrates higher prevalence rates for sexual harassment for particular groups across multiple identity categories, including women with disabilities. ${ }^{1}$ Nine out of ten (89 percent) women with disability and almost seven out of ten (68 percent) men with disability have been sexually harassed in their lifetimes. People with disability were also more likely than those without disability to have been sexually harassed in the workplace (44 percent and 32 percent, respectively). Both men ( 35 percent) and women ( 52 percent) with disability were more likely than those without disability to have experienced workplace sexual harassment during the last five years (Australian Human Rights Commission 2018, p. 28). The Australian Bureau of Statistics has also found that women with a disability or long-term health condition were more likely to experience sexual harassment in the twelve months prior to the survey than women without a disability or long-term health condition (19 percent or 561,300 compared to 17 percent or 1.1 million). Men with disability experienced sexual harassment at the same rate as men without disability (Australian Bureau of Statistics 2016).

It is clear from this data that sexual harassment is more prevalent on the basis of sex and disability. However, these prevalence rates are not reflected in publicly available Australian complaints data (Australian Human Rights Commission 2012), or in case law, indicating a hurdle or road block in the

1 Sexual harassment comprises a range of behaviours including unwelcome touching, inappropriate staring or leering, sexual gestures, repeated or inappropriate invitations to go out on dates, intrusive questions about one's private life or physical appearance, inappropriate physical contact, sexually suggestive comments or jokes, requests or pressure for sex or other sexual acts and actual or attempted rape or sexual assault (Australian Human Rights Commission 2018, p. 12). 
system that is even greater than that experienced by non-disabled claimants. Whether this hurdle is a legal one that might be remedied by law reform, or whether it lies elsewhere, is an important question, but rather than consider this in the abstract, I turn to the specific situation of women with challenging behaviour or personality disorders.

\section{Sexual Harassment of Women with Behavioural and Personality Disorders}

Within the broad 'category' of disability, there are very different experiences of harassment, demonstrating the need for an intersectional approach that interrogates experiences within and between discrimination law categories. Intersectional vulnerabilities to harassment vary between people with different types of disabilities, in prevalence as well as in their nature.

People with physical disabilities can be subjected to damaging stereotypes of being sexless: devoid of both desire and desirability (McSherry and Somerville 1998; Shakespeare et al. 1996; Shildrick 2007; Shuttleworth 2001). Assumptions about credibility that plague sexual harassment and sexual assault claims - that women invent or exaggerate claims of harassment or gendered abuse — can be exacerbated for women with a disability. Stereotypes that women with disabilities are asexual undermine the credibility of claimants, suggesting that they are unlikely objects of unwanted sexual behaviour.

Women with behavioural and personality disorders, in contrast, may be more likely to be seen as hypersexual, exhibiting sexually or gender-inappropriate behavior, making them both more vulnerable to harassment and their claims that the behavior was "unwanted" less readily believed. While there is scant research in the field, Shaw, Chan and McMahon, in the United States context, found that people with behavioural impairments were the most likely of disability groups to experience harassment, but less likely to successfully bring a claim. Drawing on national data, they found that rates of harassment of persons with disabilities were much higher for women with behavioural impairments (along with First Peoples, Hispanic and Asian women; and women who were 35 years of age or older) (Shaw et al. 2012, pp. 85-88).

Barnett's 2017 smaller study of adults on the autism spectrum in the United States found that harassment of people on the autism spectrum often relied on gendered assumptions and that the "conflation of disability, gender and sexuality" determined who was targeted for harassment (Barnett 2017, p. 1216). For example, people in this group were less able, because of their autistic traits, to correctly "perform" gender roles, which left them exposed to harassment. The author concluded that harassment that appeared "sexual" had hidden ableist impacts: "harassment that is nominally gender and/or sexuality based often targets impairment effects, acting as a mechanism of social disablement" (Barnett 2017, p. 1220). As with the Shaw, Chan and McMahon study above, Barnett suggests that behavioural impairments make people particular targets of harassment: "deviation of comportment is more closely policed than deviation of physical functioning" (Barnett 2017, p. 1212).

Turning to people with personality disorders, the picture is even more complex. I have written elsewhere (Karpin and O'Connell forthcoming) about the way that borderline personality disorder and histrionic personality disorder have troubling gendered histories and are strongly associated with prior abuse. Presumptions about the sexual behavior of those with personality disorders have been built into their diagnoses, for example, in the Diagnostic and Statistical Manual of Mental Disorders (DSM-V), despite the sparsity of empirical evidence of a connection between the two when the diagnoses were developed. Apt and Hurlbert noted in 1994 that "although various sexual problems have been associated with histrionic personality disorders in the literature, there has been a void in controlled comparative research regarding the sexual attitudes, behavior, and the relationships of such individuals" (Apt and Hurlbert, p. 126). While empirical studies have substantiated a number of patterns in the sexual behavior of women with personality disorders, it remains to be questioned whether these sexual traits are "problems" specifically when attributed to women. They include being promiscuous (Hull et al. 1993; Sansone and Wiederman 2009) and having a large number of sexual partners (Sansone and Wiederman 2009; Sansone et al. 2011), having extramarital affairs (Apt and Hurlbert 1994) and engaging in homosexual experiences (Neeleman 2007; Sansone et al. 2008). 
In a legal setting, these presumptions about the problematic nature of women's sexual behavior are compounded by the way that a background of sexual abuse in a claimant with a personality disorder can be used to discredit their complaint of sexual harassment. This is significant given the very high correlation of prior sexual abuse with diagnoses of personality disorder. Ideas that victims of prior sexual abuse are "hypersensitive" to sexual behaviour or compulsively seek to "re-enact the victim role" are present in the literature (Feldman-Schorrig 1996, p. 388; Feldman-Schorrig and McDonald 1992, p. 15) and in the United States have played out in courtroom defence strategies (Reed et al. 2016). This is despite studies showing that prior victimization does not account for mental harm sustained as a result of sexual harassment (see Reed et al. 2016; Stockdale et al. 2009) and that victims of prior sexual abuse are not "hypersensitive" to sexual harassment (Stockdale et al. 2002).

Where presumptions are made about the unreliability and inappropriate sexuality of women with Borderline Personality Disorder (BPD) and Histrionic Personality Disorder, compounded by their association with abuse, it is clear that making a claim of sexual harassment could be particularly fraught. While few cases exist in Australia, a sample is discussed below, and two cases involving sexual harassment of people with histrionic personality traits are explored in detail.

For the very stigmatized group of complainants with BPD in particular-BPD is considered the most stigmatized of all personality disorders (Nehls 1998; Sheehan et al. 2016)—but also, other disorders that are disproportionately diagnosed in women-including histrionic personality disorder, with its roots in the "female malady" of hysteria-discrimination law should offer protection against that stigmatization. Discrimination law frameworks are, after all, designed with the object of furthering equality, and could be expected to provide protection against unfavorable treatment affecting both women and people with disability, including personality disorders. In Australia, as set out below, there are legislative provisions allowing decision-makers to consider the relevant circumstances of an allegation in determining whether unlawful harassment took place. However, recent cases in Australia, dealing with the sexual harassment of people with personality disorders or mental illness, suggest that these provisions may in fact be used to undermine a legal claim of sexual harassment by a person with disability rather than strengthen it.

\section{Legal Approaches to Intersectional Sexual Harassment}

Intersectional discrimination against women and girls with disabilities is referenced in Article 6 of the 2007 UN Convention on the Rights of Persons with Disabilities (CRPD). However, it does not directly address violence against women with disabilities or sexual harassment. Nor does the main "women's treaty", the UN Convention on the Elimination of All Forms of Discrimination Against Women, deal directly with sexual harassment or disability. More recent international human rights work is starting to acknowledge the gap. In November 2018, The United Nations (UN) called for "urgent and thoughtful" work on sexual harassment, stating in the first of its "ten essentials" that addressing intersectional sexual harassment is a priority area (Sen 2018). The most recent UN report points out that, as well as the crucial need to address intersectional harassment, intersectional factors work to privilege certain abusers as well as marginalize certain claimants (Sen 2019).

In Australia, where anti-discrimination legislation has been the primary means of meeting our international human rights commitments to equality, one legislative attempt to address intersectional factors in sexual harassment is embedded in the Sex Discrimination Act 1984 (Cth) (the Act). A section (s28A(1A)) was added to the Act in 2011, that lists as relevant "circumstances" identity characteristics of the harassed person (including their race, disability and age), as well as their relationship to the harasser, as factors to be taken into account in finding sexual harassment unlawful. ${ }^{2}$ In determining

2 A few State jurisdictions have equivalent provisions. See Section 120 of the Anti-Discrimination Act 1991 (Qld); Anti-Discrimination Act 1992 (NT), Section 22(3); Anti-Discrimination Act 1998 (Tas): Section 17 defines sexual harassment, but there is no equivalent "relevant circumstances" provision. However, s 17 prohibits not just sexual harassment but also, 
whether a person would have reasonably anticipated the possibility that the behavior was offensive, humiliating or intimidating, section 28A Sex Discrimination Act 1984 (Cth) states:

(1A) For the purposes of subsection (1), the circumstances to be taken into account include, but are not limited to, the following:

(a) the sex, age, sexual orientation, gender identity, intersex status, marital or relationship status, religious belief, race, colour, or national or ethnic origin, of the person harassed;

(b) the relationship between the person harassed and the person who made the advance or request or who engaged in the conduct;

(c) any disability of the person harassed;

(d) any other relevant circumstance.

Sexual harassment law does, therefore, on its face, attempt to acknowledge disability along with other relevant characteristics of the harassed person. While this reform was presumably to address the intersectional nature of harassment through attention to all relevant circumstances, acknowledgement that this was the purpose of this section is minimal, in either the law reform material underpinning the changes or the explanatory memorandum or second reading speeches of the reform Bill. In the absence of any legislative statement to the contrary, or any powerful extrinsic materials to claim otherwise, nothing in this section requires that these circumstances are relevant to establishing the greater vulnerability of groups to harassment, not does it prevent a decision-maker using this to the claimant's detriment. The avowed neutrality of anti-discrimination laws, applying equally to privileged and disadvantaged groups, means that they may be used against the very groups they were intended to protect and redress.

Nevertheless, section $28 \mathrm{~A}(1 \mathrm{~A})$ could still be used to address the higher incidence of harassment against the groups identified by the AHRC and the ABS data. However, despite the promise of this intersectionality provision, the sub-section is mostly overlooked or haphazardly applied by decision-makers. In a three-year research period (2015-2018), there were three cases that directly considered s28A (Chen $v$ Monash University [2015] FCA 130; TN v BF \& Anor [2015] FCCA 1497; Wroughton $v$ Catholic Education Office Diocese of Perth [2015] FCA 1236). In two of the cases, the relevant intersectional factor or factors are only mentioned, with nothing substantive drawn from them. Only one of the judgments actually sets out s28A (1A): Chen $v$ Monash University, where the judge "adopted a cautious approach in assessing [the applicant's] evidence" and "took into account" that English was not the applicant's first language and that "there may well have been times where her expression may have led to misunderstandings between her and her male colleagues".

In the small sample of cases with claimants with mental health or personality disorders, respondents will point to pre-existing psychiatric illness to discredit an applicant's claims (TN v BF \& Anor [2015] FCCA 1497; Mathews v Winslow Constructors (Vic) Pty Ltd [2015] VSC 728; STU v JKL (Qld) Pty Ltd and Ors [2016] QCAT 505), with limited success. Judges seem to be more likely to take an applicant's mental illness into account when considering the circumstances of harassment, albeit without acknowledging s28A(1A) (Green $v$ State of Queensland, Brooker and Keating [2017] QCAT 8; Kordas v Ruba [2017] NSWCATAD 156). For example, the putative personality disorder of the applicant is referenced in $T N$ $v B F(2015)$ where the judge uses expert evidence that the (female) applicant's behaviour "is consistent with someone having histrionic personality disorder" to conclude that there is 'insufficient evidence' to establish sexual harassment under the Act. In a Queensland case (interpreting the section of the Queensland Anti-Discrimination Act that is replicated in the federal law), Green $v$ State of Queensland, Brooker and Keating (2017), the pre-existing personality disorder of the person who was harassed is also referenced. However, in Green, the (male) alleged victim's reported "histrionic personality traits"

harassment on the basis of gender, race, age, sexual orientation, gender identity, intersex status, disability, marital status, relationship status, pregnancy, breastfeeding, parental status and family responsibilities. 
were used to "explain a lot of the inconsistencies" and exaggerations in his evidence, to positive effect. These two cases are analysed in depth below.

In other cases, mental illness, even where it seems relevant as a compounding factor for harm, is barely acknowledged. In Kordas $v$ Ruba (2017), the vulnerability of the applicant as a result of his pre-existing mental illness was considered only as a factor in assessing damages. In STU $v$ JKL (2016), another Queensland case, the fact that the applicant may have had a pre-existing psychological condition was considered only in the context of evaluating the extent to which her injury was caused by the sexual harassment.

\section{Two Cases on Sexual Harassment against Claimants with Personality Disorders}

In the sexual harassment case, TN $v$ BF \& Anor (2015), the contention that the woman reporting the unwanted behavior had histrionic and borderline traits worked against her case in two key ways: her evidence that she was sexually harassed is not believed, in part because of the purportedly "seductive" and "overly sexual" behavior associated with histrionic personality disorder, and she is considered to be "malingering", in part because of the traits of attention-seeking and "emotionality" associated with BPD.

In the case, TN, a Vietnamese woman in her mid-twenties for whom English was a second-language, took a job as a salesperson at the family company, identified in the case by the initials BF. The founder of the company, an elderly man called $\mathrm{AB}$, still attended the workplace, although he played no active role in running the company. He had two other female employees, described as a secretary or personal assistant and a receptionist, who personally attended to him. The secretary's duties included "... taking $\mathrm{AB}$ to and from work and to other appointments, assisting him in cutting his nails, trimming his eyebrows and other tasks" (TN v BF \& Anor 2015, para. 17). The secretary and receptionist also ate lunch alone with $\mathrm{AB}$ every day, and so seemed to have more companionship and personal care roles than conventional administrative duties.

When $\mathrm{TN}$ attended her job interview for the company, it was $\mathrm{AB}$, despite his lack of a management role, who interviewed her, with his personal assistant present. One of the main points of contention in the case happened when $\mathrm{TN}$ was asked by $\mathrm{AB}$ to return for a second interview on a Sunday, three days later. TN says that at this interview, AB told her to lift up her skirt and masturbate, which she refused to do, and that he started masturbating. $\mathrm{AB}$ was not present to give evidence in the case, as in the intervening period he had grown frail and was in a care facility, but in his affidavit claimed that he had commented critically on TN's skirt length, saying that she needed to wear more appropriate attire, and that, in response, she had said "how about this?" and lifted up her skirt and started masturbating (TN $v$ BF \& Anor 2015, para. 104). He then states that he masturbated in response. In a separate incident, a few days later, he admits to masturbating again, in the presence of both TN and his receptionist. TN videoed $A B$ on her phone without his knowledge, while he masturbated for four and a half minutes. In her affidavit TN said: "I was disgusted though did not want to leave as I did not want to lose my job. I was waiting for him to ejaculate so that I could leave the room" (TN v BF \& Anor 2015, para. 49).

To be unlawful, sexual harassment has to be unwelcome. In assessing the second interview incident the judge states:

$\mathrm{AB}$ [in his statement claimed that he] observed that $\mathrm{TN}$ was wearing a skirt that was short and he said to TN that she needed to wear more suitable attire in her sales role, to which she responded by standing up and pulling up her skirt and saying 'how about this?' AB says that he asked TN to masturbate and she proceeded to do so while he also masturbated. AB stated that TN did not appear uncomfortable. TN denies that this occurred, but this type of behaviour is the sort that would be expected from a person suffering from personality disorder with histrionic traits. (TN v BF \& Anor 2015, para. 104) (my emphasis)

The claim that TN spontaneously started masturbating in a job interview is treated as credible by the judge solely because of her putative personality disorder. The judge reports that one of the doctors 
giving evidence, Dr Benjamin, "agreed that this type of behaviour was consistent with someone who had histrionic personality disorder" (TN v BF \& Anor 2015, para. 105). The judge relies on the following oral evidence:

Canceri [AB's lawyer]: Can I just get you to assume this scenario. A female in her mid-twenties goes to a job interview. It's her second job interview. And during that interview with the prospective employer, she pulls up her skirt in front of the prospective employer and says words to the effect of, what about this? And that's in response to the prospective employer making a comment about the business attire being worn by the applicant. And then that prospective employee or applicant then touches her genital area in a provocative way. Is that the type of behaviour consistent with someone exhibiting histrionic personality disorder?

Dr Benjamin: Yes. People with histrionic personality often act in a seductive and over-sexual manner. If this was true-I don't know if that was true, but that- that would be -- -

Canceri: No, just assuming --- ?

Dr Benjamin: Yes.

Canceri: - - - that factual scenario?

Dr Benjamin: Yes.

(TN v BF \& Anor 2015, para. 105)

There is no other evidence referred to in the case that suggests that TN behaves "seductively" or has sexual issues. The mere existence of the list of traits in the Diagnostic and Statistical Manual of Mental Disorders (American Psychiatric Association 2013) ("DSM-V"), along with a doctor's statement about seductiveness as a trait of the category of people with histrionic personality disorder, is sufficient. Yet, seductiveness is mentioned in only one of eight traits of the disorder in the DSM-V, of which only five need to be satisfied, meaning that many people could be diagnosed with histrionic personality disorder without having this trait at all. In the alternative diagnostic tool, the World Health Organisation's International Classification of Diseases, seductiveness is not mentioned in any of the ten traits (World Health Organisation 2018). ${ }^{3}$

Further, and more worrying, is the gendered nature of the trait. "Seductive" is a particularly gendered term, and a search for cases in which men with histrionic traits were described as "seductive" unsurprisingly yielded nothing. In fact, in the case there is incontrovertible evidence that $A B$, the alleged perpetrator, behaved in "inappropriate sexually seductive or provocative" ways, given his admission that he masturbated in front of staff in the workplace and the relatively lengthy video of him doing so. It is $\mathrm{TN}$ who has the onus of proving the case, but even so, it is a strange inversion of her claim of harassment that she is unsuccessful in significant part because of sexual behavior ascribed to her on the basis of a descriptive category of disability to which she may not even belong, while a man who admits to masturbating in front of staff and making sexual comments to them evades any such label. ${ }^{4}$

In addition to disbelieving TN's version of the first claimed incident of harassment-that it was $\mathrm{AB}$ who commented on her appearance in a sexual way and masturbated-TN's alleged personality

3 The World Health Organisation, ICD-10, traits of histrionic personality disorder are as follows. A personality disorder characterized by: shallow and labile affectivity, self-dramatization, theatricality, exaggerated expression of emotions, suggestibility, egocentricity, self-indulgence, lack of consideration for others, easily hurt feelings, and continuous seeking for appreciation, excitement and attention.

4 "Given the evidence of Dr Benjamin that the behaviour suggested to him is consistent with someone having histrionic personality disorder and the doctor's diagnosis that TN exhibited traits of borderline and histrionic personality disorder, there is insufficient evidence before this Court in relation to the incident on 3 May 2009 to establish what occurred other than what is contained in the video footage (Exhibit "R7")" (TN v BF \& Anor 2015, para. 106). 
disorder also seems to go to a more general lack of credibility before the law. ${ }^{5}$ The general lack of credibility that the judge found in relation to TN meant that she was required to provide corroborating evidence to discharge the onus of proof. Since she had not done this, her evidence alone was insufficient.

TN's personality is also one of the reasons that she is unsuccessful in her claim that she was harmed by AB's behavior. She claimed to have had serious psychiatric consequences arising from the harassment, including a suicide attempt. However, a doctor who briefly examined her after an episode of self-harm gave evidence that was accepted by the judge, that TN was "malingering". This view was based on a few minutes' examination of TN around the time that she sought medical care after cutting her wrist. The judge disregards the shortness of the examination, which otherwise might undermine its veracity, because the length of the assessment was, in his view, TN's own fault: she "was completely uncooperative, as was her husband" (TN v BF \& Anor 2015, para. 108). This was because TN wanted her husband, who was beside her, holding their baby, to stay with her. "[De]spite Dr Akkerman's request that her husband remain in the waiting room with the baby as it was not conducive to conduct an examination process in the presence of a young baby, the request was ignored by TN's husband" (TN $v$ BF \& Anor 2015, para. 108). The judge also adds that "Dr Akkerman noted that TN clung to her husband's arm in an exaggerated manner saying that she wanted her husband to be present" (TN $v B F$ $\mathcal{E}$ Anor 2015, para. 108).

Eventually, after TN agreed to be examined alone, she was described by the doctor as "irritable and uncooperative". Evidence for this was that in response to Dr Akkerman asking TN about her symptom she responded "you have the paperwork, why are you asking me all these questions?" The judge accepts this evidence:

[T] he opinion that TN is malingering is consistent with the opinion of Dr Benjamin that TN suffered from a pre-existing personality disorder, mainly with histrionic and borderline traits. The extract on histrionic personality disorder (Exhibit "R11", American Psychiatric Association, Diagnostic and Statistical Manual of Mental Disorders, 5th ed. (DSM-V), May 2013, p. 667 [301.50]) refers to self-traumatisation, theatricality and exaggerated expressions of emotion as some of the 'Diagnostic Criteria' of histrionic personality disorder. The full list is as follows:

A persuasive pattern of excessive emotionality and attention seeking, beginning by early adulthood and present in a variety of contexts, as indicated by five (or more) of the following:

1. Is uncomfortable in situations in which he or she is not the centre of attention.

2. Interaction with others is often characterised by inappropriate sexually seductive or provocative behaviour.

3. Displays rapidly shifting and shallow expression of emotions.

4. Consistently uses physical appearance to draw attention to self.

5. Has a style of speech that is excessively impressionistic and lacking in detail.

6. Shows self-determination, theatricality, and exaggerated expression of emotion.

7. Is suggestable (i.e., easily influenced by others or circumstances).

8. Considers relationships to be more intimate than they actually are.

The extract states that an essential feature of histrionic personality disorder is persuasive and excessive emotionality and attention-seeking behaviour. This material, together with the credibility issues above, confirms that it is not possible to establish that TN has proved her case on the balance of probabilities. (TN $v B F \mathcal{E}$ Anor 2015, paras. 110, 111)

5 "The Court has been invited to be critical of both TN's Police Statements on the basis of TN's propensity to exaggerate and embellish..." (TN v BF \& Anor 2015, para. 107). 
In setting out his understanding of histrionic personality disorder, the judge significantly misquotes the DSM-V twice. The definition refers to "self-dramatization", but the judge wrongly calls it "self-traumatisation", and then follows this with a list of traits in which he again substitutes an incorrect term, this time replacing "self-dramatization" with "self-determination." The judge's incapacity to master the terminology while relying on it is concerning. Second, he treats the complainant as if putting her in a category of "histrionic personality disorder" makes her presumptively, and consistently, possess all of the traits listed, despite those traits not being required for a diagnosis. Third, the gendered nature of those traits (specifically 'seductiveness') is not acknowledged in any way or even visible to the judge. Finally, there is the failure to take an intersectional approach to harassment.

Age and race are clearly potential exacerbating factors in sexual harassment cases in that both young women, and women from minority groups, particularly vulnerable workers, are disproportionately targets of harassment (Australian Human Rights Commission 2018). In this case, we have a young Vietnamese woman, purportedly with traits of a histrionic personality disorder. Her age, race and sex should all be taken into account as potentially relevant circumstances under s28A(1A). However, TN's race is only referenced in relation to a possible need for an interpreter. When, for example, she explains her failure to leave the room while $A B$ is masturbating as being because she is scared she will lose her job, race is not mentioned. We are not told $\mathrm{AB}^{\prime}$ s race. Whether, for example, TN is vulnerable in an employment context, as a young Vietnamese woman whose first language is not English, does not factor in the case.

We also know that personality disorders are the most stigmatized of all disorders and that they have worrying traces of negatively gendered and raced histories and stereotypes (Nehls 1998; Sheehan et al. 2016; McGilloway et al. 2010). TN's potential disability is acknowledged in the case, but as a factor undermining her credibility, not as an intersectional disadvantage that makes her vulnerable to sexual harassment.

A comparison can be made between this case and the case of Green $v$ State of Queensland, Brooker and Keating [2017] QCAT 8 (Green v Queensland), which involved a sexual harassment complaint under the Anti-Discrimination Act 1991 (Qld), State legislative provisions written in substantially the same terms as the federal legislation. The claim was made by a male employee who had, like TN, been found to have histrionic personality traits. The expert psychiatrist and his treating psychiatrist stopped short of diagnosing a disorder. But, unlike TN, whose "diagnosis" came from the doctor assigned to her by her worker's compensation scheme and was also described in terms of traits (leaving it unclear whether in fact she had a disorder, or merely some traits), Green's histrionic traits did not undermine his case. In fact, they were either discounted or used as positive evidence of his credibility, whereas TN's traits were used to discredit hers.

Green was subject to a workplace prank that he alleged constituted sexual harassment when he was employed by the State of Queensland as a school cleaner. The Respondents, a male groundkeeper and a female cleaner, set up a room that Green was to clean with condoms, underwear and wine bottles, as if a "sex romp" had taken place. They alleged that Green feigned his response to the prank in order to obtain compensation. This was supported by the opinion of a psychiatrist who believed that Green did not have any psychological injury as a result of the prank. The psychiatrist did, however, suggest that Green might have histrionic personality traits, a view which was supported by Green's treating psychiatrist. However, it was not suggested Green suffered from a personality disorder and it was not the Respondent's case that Green's reaction to events were a result of his personality disorder rather than sexual harassment.

Green's reaction to finding out that the supposed "sex romp" was in fact a prank, was to fall to his knees, with a big smile on his face. The tribunal member treated this behavior, including the smile, not as a discrediting degree of emotionality, nor as an acceptance that it was a joke, but as "his way of attempting to cope with the humiliation" (Green v Queensland 2017, para. 94). Humiliation is a key legal element in proving sexual harassment. In contrast, TN's recording of the video constituted 
evidence that she was not humiliated, since she had stayed to make the recording. Further, Green's theatricality was described as a marker of normality.

[E]veryone is unanimous that it was normal for Mr Green to show his feelings in such a theatrical way, and nothing turns on this particular behaviour. (Green v Queensland 2017, para. 94)

Despite Green's inconsistent evidence, which was at odds with material evidence in the case and was internally contradictory, along with evidence of his tendency to exaggerate and be theatrical, Green was seen as a fundamentally credible witness. Where Green's evidence is wrong, the tribunal member takes that as proof of his inherent honesty, on the basis that if Green was trying to be dishonest, he would have done a better job of it. For example, when Green insisted that the "sex romp" room was set up in a particular way that was contradicted by photographic evidence, the tribunal member, in declining to read this as undermining his credibility, said the following:

The question of guile must be considered in the light of the accepted fact that Mr Green had no intellectual deficiencies, and that he did do some acting work as a film extra. (Green $v$ Queensland 2017, para. 87)

There are a number of things, however, which emerged at the hearing which make it very unlikely that Mr Green made up his reaction to the events in this way. [The tribunal member spells out Mr Greens' inaccuracies and concludes:] What Mr Green was saying about this was highly unlikely, and had Mr Green been sufficiently artful to make up his reaction to the events, I think he would have relented and accepted that he was mistaken about this. (Green $v$ Queensland 2017, para. 88)

As well as Green's inaccuracies going to his credibility, even his work as a part-time actor does not evidence any suspect theatricality.

It is important to point out that in analysing Green's case, I am not saying that the law should have been more punitive to him. In fact, it is a decision much less marked by stereotype and negative assumptions about people with histrionic personality traits. However, Green, being male, seems to have eluded the negative and gendered elements of being purportedly "histrionic" that undermined $\mathrm{TN}$. It is also worth noting there are significant material consequences that attach to such a loss of credibility for complainants such as TN. Green's compensation for non-financial loss in the matter was high, exceptionally high in the overall history of sexual harassment compensation. It was even high when considered in light of the more recent case law that has developed following the case of Richardson $v$ Oracle Corporation Australia Pty Ltd [2014] FCAFC 82. This case attempted to redress the long history of very small compensation payouts to victims of sexual harassment and allowed for at least the prospect of more appropriate compensation. For example, the sexual harassment case of STU v JKL (Qld) Pty Ltd and Ors [2016] QCAT 505 (STU v JKL), under the same legislation, jurisdiction and tribunal as Green's, concerned a 21-year-old female hotel employee who was woken from sleep and sexually assaulted in her bedroom by her 70-year-old work colleague while housed in the same accommodation as him.

She suffered a post-traumatic stress disorder and a depressive illness which continued for a period of at least nearly four years ... (STU v JKL 2016, para. 209)

Member Fitzpatrick declined to follow Richardson and the more generous amounts allowed for in that case despite being invited to do so. (STU v JKL 2016, paras. 218-220)

While the tribunal in Green did not ultimately follow Richardson-although it considered at length doing so-it used STU $v$ JKL as a comparator case for damages, saying that while the offence was more serious, the effects were comparable. Green was paid the same amount of non-financial compensation for the prank as the complainant in STU $v$ JKL was paid for being sexually assaulted at work: $\$ 70,000$, and $\$ 156,051$ altogether. 


\section{Conclusions}

While these few particular examples do not provide sufficient evidence to draw general conclusions about sexual harassment cases with complainants with mental health and personality disorders, they do demonstrate some significant points about the gendered nature of personality disorders before the law.

First, personality traits and disorders can be applied in sexual harassment cases in ways that either powerfully exacerbate or disregard gendered stereotypes that have been historically used to stigmatize women. In TN's case, her histrionic traits made her presumptively seductive and lack credibility in ways that fatally undid her legal claim.

Second, the obscured gendered histories of histrionic and borderline personality disorders can mean these laden words and concepts can be applied in law with no acknowledgment-and likely no understanding - that they are potentially being applied in ways that perpetuate gendered harm.

Finally, the fact that personality disorders that are highly associated with trauma are not so acknowledged, means that there is a continuation of the positioning of trauma in the woman, rather than in external events. While we do not know about TN's past experiences, her actions in the case are not seen in a context of possible past gender-based trauma, exacerbated by further of the same. While we cannot know if this is the case (but perhaps should), it is clear that her behavior is viewed as a manifestation of a compromised internal environment, rather than, say, the rational reaction of a women to a potentially threatening external environment.

The way personality disorders are treated, in clinical definitions such as those in the DSM and $I C D$, and the way they are translated into law, replicate inequalities. They rely on simple taxonomies of traits, and despite the quite devastating critiques of the ways these transcribe negative stereotypes about women from one powerful discipline to the next, they continue relatively unchanged. They rely on, and in turn allow law to rely on, outmoded ideas about women's emotionality and sexuality, amplified by the lack of credibility and hypersexuality attributed to women with these particular attributions of disability.

The existence of a section in the federal Sex Discrimination Act that could be used to address intersectional factors in sexual harassment is clearly insufficient. Any practical significance of the provision seems to have evaporated. It appears to make no difference at all in the case law, and even its presumptive origins in addressing intersectionality has not left a trace in the law reform materials and legislative record of the time. It may as well not exist.

A clear implication of this research is that in order to address intersectional sexual harassment we, at the very least, need a provision that cannot be overlooked. The provision should require rather than permit a decision-maker to consider factors of age, race, disability, sexuality and similar in considering the circumstances of sexual harassment. The persistence of stereotypes and stigma even in the case law that sets out to remedy it also invites more comprehensive reform. However, this alone would not be sufficient. Negative stereotypes and presumptions about women with behavioural and personality disorders will continue to contaminate legal decision-making if they are not exposed. In TN's case, sexually inappropriate behavior was attached to her, even in a fact situation that did not justify it. Considering, in detail, the intersectional experiences of women shows that if these stereotypes and stigmas are not made visible, they will simply perpetuate, even in the area of law that is designed to remedy them.

Laws that recognise gendered harms, such as sexual harassment laws, developed in the 1980s, are relatively new and are anchored in sociological and political developments that are more attuned to the reality of women's lived experiences. The feminist activism and political and legal reforms that instituted them were genuinely innovative for their time. As these laws age, and we see the stereotypes and stigma they have failed to dislodge, and the people they continue to exclude, we need to continually develop new approaches. Feminist critique of personality disorders has revealed the historical and contemporary misuse of the diagnosis. Focusing on the lived experience of intersectional sexual harassment shows how that diagnosis is incorporated into law in equally troubling ways. 
Inequality and stigma have insidious effects as they work their way into law, even laws that are purportedly beneficial, such as anti-discrimination and sexual harassment laws. We need feminist and intersectional perspectives to reveal these effects and to make laws that better address inequality.

Feminist theory and activism that is anchored in intersectionality should underpin the next push for legal and social reform so that our equality laws acknowledge and remedy intersectional gendered harm.

Funding: This paper includes research undertaken with Distinguished Professor Isabel Karpin (University of Technology Sydney) on the Australia Research Council Discovery Grant (DP150102935) 'The Legal Regulation of Behaviour as a Disability'.

Acknowledgments: This work was supported by an Australian Research Council grant [DP150102935] Regulating Behaviour as a Disability. Distinguished Professor Isabel Karpin (University of Technology Sydney) collaborated on the research for this article as well as many of the ideas underpinning it. Liam Elphick, Ruby Lew, Ada MacIntyre and Ruby Wawn provided excellent research assistance.

Conflicts of Interest: The author declares no conflict of interest.

\section{References}

\section{Archival Sources}

Cases:

Chen $v$ Monash University [2015] FCA 130

Green $v$ State of Queensland, Brooker and Keating [2017] QCAT 8

Kordas v Ruba [2017] NSWCATAD 156

Mathews v Winslow Constructors (Vic) Pty Ltd [2015] VSC 728

Richardson $v$ Oracle Corporation Australia Pty Ltd [2014] FCAFC 82

STU v JKL (Qld) Pty Ltd and Ors [2016] QCAT 505

TN v BF \& Anor [2015] FCCA 1497

Wroughton v Catholic Education Office Diocese of Perth [2015] FCA 1236

Legislation:

Anti-Discrimination Act 2010 (Qld)

Sex Discrimination Act 1984 (Cth)

\section{Published Sources}

American Psychiatric Association. 2013. Diagnostic and Statistical Manual of Mental Disorders, 5th ed. Washington, DC: American Psychiatric Association Publishing.

Apt, Carol, and Farley Hurlbert. 1994. The sexual attitudes, behaviour, and relationships of women with histrionic personality disorder. Journal of Sex E Marital Therapy 20: 125-34.

Australian Bureau of Statistics. 2016. Personal Safety Survey. cat. no. 4906.0. Canberra: ABS.

Australian Human Rights Commission. 2012. Conciliation Register; Sydney: AHRC. Available online: https: //www.humanrights.gov.au/complaints/conciliation-register (accessed on 5 December 2019).

Australian Human Rights Commission. 2018. Everyone's Business: Fourth National Survey on Sexual Harassment in Australian Workplaces. Sydney: AHRC.

Barnett, Jessica Penwell. 2017. Intersectional harassment and deviant embodiment among Autistic adults: (dis) ability, gender and sexuality. Culture, Health E Sexuality 19: 1210-24.

Buchanan, NiCole, Isis Settles, Ivan Wu, and Diane Hayashino. 2018. Sexual Harassment, Racial Harassment, and Well-Being among Asian American Women: An Intersectional Approach. Women E Therapy 41: 261-80.

Calafell, Bernadette. 2014. “Did it happen because of your race or sex?" University sexual harassment policies and the move against intersectionality. Frontiers: A Journal of Women Studies 35: 75-95. [CrossRef]

Carbado, Devon, Kimberle Crenshaw, Vickie Mays, and Barbara Tomlinson. 2013. Intersectionality: Mapping the Movements of a Theory. Du Bois Review: Social Science Research on Race 10: 303-12. [CrossRef]

Chi Cantalupo, Nancy. 2019. And Even More of Us Are Brave: Intersectionality \& Sexual Harassment of Women Students of Color. Harvard Journal of Law and Gender 42: 3-79. 
Crenshaw, Kimberle. 1989. Demarginalizing the Intersection of Race and Sex: A Black Feminist Critique of Antidiscrimination Doctrine, Feminist Theory and Antiracist Politics. University of Chicago Legal Forum 1989: 139-67.

Feldman-Schorrig, Sara. 1996. Factitious sexual harassment. Bulletin of the American Academy of Psychiatry Law 24: 387-92.

Feldman-Schorrig, Sara, and James McDonald. 1992. The role of forensic psychiatry in the defense of sexual harassment cases. Journal of Psychiatry E Law 20: 5-33.

Goldblatt, Beth. 2015. Intersectionality in international anti-discrimination law: Addressing poverty in its complexity. Australian Journal of Human Rights 21: 47-70. [CrossRef]

Hull, James, John Clarkin, and Frank Yeomans. 1993. Borderline personality disorder and impulsive sexual behavior. Hospital \& Community Psychiatry 44: 1000-2.

Karpin, Isabel, and Karen O'Connell. Forthcoming. Disability and the Institution of Justice: An examination of case law involving personality disorders. In The Legacies of Institutionalisation: Disability, Law and Policy in the 'Deinstitutionalised' Community. Edited by Claire Spivakovsky, Linda Steele and Penelope Weller. London: Hart Publishing.

McGilloway, Angela, Ruth E. Hall, Tennyson Lee, and Kamaldeep S. Bhui. 2010. A systematic review of personality disorder, race and ethnicity: Prevalence, Aetiology and treatment. BMC Psychiatry 10: 33-47. [CrossRef] [PubMed]

MacKinnon, Catharine. 1979. Sexual Harassment of Working Women: A Case of Sex Discrimination. New Haven: Yale University Press.

McSherry, Bernadette, and Margaret Somerville. 1998. Sexual Activity among Institutionalized Persons in Need of Special Care. Windsor Yearbook Access to Justice 16: 90-134.

Mitchell, Kimberly, Michele Ybarra, and Josephine Korchmaros. 2014. Sexual Harassment among Adolescents of Different Sexual Orientations and Gender Identities. Child Abuse E Neglect 38: 280-95.

Neeleman, Albert. 2007. The relevance of sexuality in the treatment of borderline personality disorder. Tijdschr Psychiatr Journal 49: 233-40.

Nehls, Nadine. 1998. Borderline Personality Disorder: Gender Stereotypes, Stigma, and Limited System of Care. Issues in Mental Health Nursing 19: 97-112. [CrossRef]

O'Connell, Karen. 2012. "A Plural Thing": Inventing a Feminist Brain-Based Subject of Law. The Australian Feminist Law Journal 37: 15-32.

Onwuachi-Willig, Angela. 2018. What About \#UsToo? The Invisbility of Race in the \#MeToo Movement. Yale Law Journal Forum 128: 105-20.

Ramakrishnan, Kavita. 2011. Inconsistent Legal Treatment of Unwanted Sexual Advances: A Study of the Homosexual Advance Defense, Street Harassment, and Sexual Harassment in the Workplace. Berkeley Journal of Gender, Law and Justice 26: 291-355.

Reed, M.E., L.L. Collinsworth, A.K. Lawson, and L.F. Fitzgerald. 2016. The Psychological Impact of Previous Victimization: Examining the "Abuse Defense" in a Sample of Harassment Litigants. Psychological Injury and Law 9: 230-40. [CrossRef]

Sansone, Randy, and Michael Wiederman. 2009. Borderline personality symptomatology, casual sexual relationships, and promiscuity. Psychiatry (Edgmont) 6: 36-40. [PubMed]

Sansone, Randy, Jacqueline Barnes, Elizabeth Muennich, and Michael Wiederman. 2008. Borderline personality symptomatology and sexual impulsivity. International Journal of Psychiatry E Medicine 38: 53-60.

Sansone, Randy, Jamie Chu, and Michael Wiederman. 2011. Sexual behaviour and borderline personality disorder among female psychiatric inpatients. International Journal of Psychiatry in Clinical Practice 15: 69-73. [CrossRef] [PubMed]

Sen, Purna. 2018. Towards an end to Sexual Harassment: The Urgency and Nature of Change in the Era of \#metoo. New York: UN Women.

Sen, Purna. 2019. What Will It Take? Promoting Cultural Change to End Sexual Harassment. New York: UN Women.

Shakespeare, Tom, Kath Gillespie Sells, and Dominic Davies. 1996. "Barriers to Being Sexual" in The Sexual Politics of Disability: Untold Desires. London: Cassell.

Shaw, Linda, Fong Chan, and Brian McMahon. 2012. Intersectionality and Disability Harassment: The Interactive Effects of Disability, Race, Age and Gender. Rehabilitation Counselling Bulletin 55: 82-91. [CrossRef] 
Sheehan, Lindsay, Katherine Nieweglowski, and Patrick Corrigan. 2016. The Stigma of Personality Disorders. Current Psychiatry Reports 18: 11. [CrossRef]

Shildrick, M. 2007. Dangerous Discourses: Disability, Anxiety and Desire. Studies in Gender and Sexuality 8: 221-44. [CrossRef]

Shuttleworth, Russell. 2001. Symbolic Contexts, Embodied Sensitivities, and the Lived Experience of Sexually Relevant Interpersonal Encounters for a Man with Severe Cerebral Palsy. In Semiotics and Dis/Ability: Interrogating Categories of Difference. Edited by Linda J. Rogers and Beth Blue Swadener. New York: SUNY Press.

Stockdale, Margaret, Maureen O'Connor, Barbara Gutek, and Tracey Geer. 2002. The relationship between prior sexual abuse and reactions to sexual harrassment: Literature review and empirical study. Psychology, Public Policy, and Law 8: 64-95. [CrossRef]

Stockdale, Margaret, T.K. Logan, and Rebecca Weston. 2009. Sexual Harassment and Posttraumatic Stress Disorder: Damage beyond Prior Abuse. Law and Human Behaviour 33: 405-18. [CrossRef]

World Health Organisation. 2018. International Classification of Diseases, 11th ed. Geneva: World Health Organisation.

(C) 2019 by the author. Licensee MDPI, Basel, Switzerland. This article is an open access article distributed under the terms and conditions of the Creative Commons Attribution (CC BY) license (http://creativecommons.org/licenses/by/4.0/). 